\title{
Modern Tendencies of Cluster Development of Regional Economic Systems
}

\author{
Elena Nikolaevna Zakharova1
}

\section{Victoria Vladimirovna Prokhorova²}

Fedor Valerievich Shutilov ${ }^{2}$

Elena Nikolaevna Klochko³

${ }^{1}$ Adygeya State University, ${ }^{2 K u b a n}$ State Technological University, ${ }^{3}$ Southern Institute of Management Email: magadan.79@mail.ru

\section{Doi:10.5901/mjss.2015.v6n5s3p154}

\section{Abstract}

The article highlights various aspects of the formation and implementation of cluster policy at regional level. Considerable role is devoted to the analysis of existing approaches to identify promising for the implementation of the cluster approach sectors of the regional economy. Also examines the main directions of state policy in the field of support cluster development due, in particular, the development of globalization and virtualization. The necessity of implementing of a synergetic approach to the assessment of the effectiveness of cluster development is being highlighted.

Keywords: globalization, virtualization, cluster competition, technique index, economy.

\section{Introduction}

In modern conditions, one of the most promising areas of the organization of economic development of the region is the cluster approach. A cluster or industrial group, by definition of $\mathrm{M}$. Porter, is a group of geographically adjacent interconnected companies and associated organizations operating in a particular area, characterized by common activities and complementary to each other Porter, Michael E. (2005).

\section{Main Part}

This interaction gives cluster members companies a competitive advantage, forming the so-called "Competitive diamond" (figure 1).

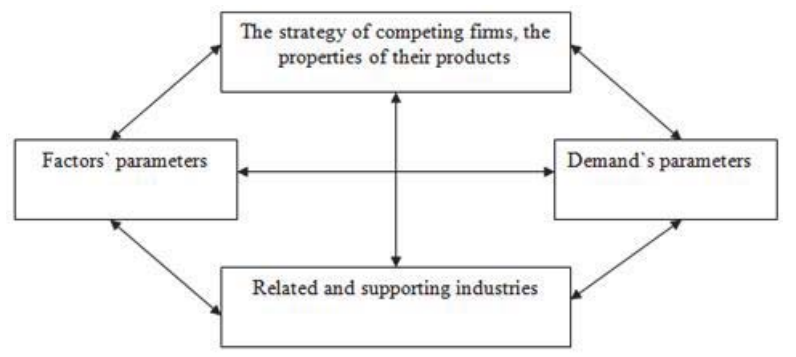

Figure 1 - "Competitive diamond" M. Porter

An analysis of foreign practice of clustering the region's economy shows that there are two models of territorial organization of cluster policy. Classical liberal model (often called Anglo-Saxon) provides a market mechanism of selfregulation of cluster initiatives, only when the state creates the necessary conditions for the formation of clusters, participating in the formation of infrastructure. Usually, liberal policies implemented in the regions of high and medium 
investment activity, have their own natural resources. Countries, which are characterized by this model, are as follows: the US, UK, Australia, Canada.

In contrast to the liberal one, dirigiste (continental) model focuses on the choice of the "points of growth" for the region. Usually, regions with low investment activity do not have rich natural resources and, in this case, it is advisable to have government intervention not only in the development of appropriate infrastructure, but also direct financial contributions to the development of the cluster. Such a policy is typical for countries such as Austria, Germany, India, Singapore, Sweden, South Korea, France, and Japan.

Considering the implementation of the cluster policy in Russia (Shutilov F.V., 2011), it should be noted that the negative features characteristic for the development of the business environment (related to the legislation, the level of corruption of officials) should be taken into account when determining the methodological basis for the formation of cluster policy. Simplified mechanism of cluster formation Zakharova EN \& Kovalev I.P. (2013) is shown in Figure 2.

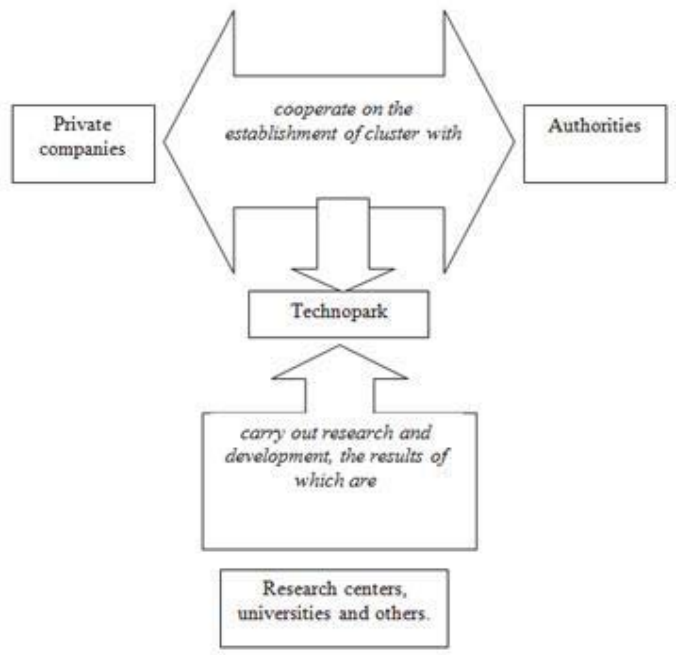

Figure 2 - A simplified mechanism for the formation of the cluster

The cluster approach in a modern economy is an important incentive for attracting foreign investment. The popularity of the cluster approach leads to the fact that large multinational companies when placing the assembly plants are selected; all other things being equal, those regions that already have formed clusters of suppliers.

If small businesses are unable to individually focus significant resources to conduct research and development activities, implementing costly marketing activities to build effective working with suppliers to obtain an additional effect on the volume associated with a savings in fixed costs, in a cluster, they can successfully confront the competition even large multinationals. The clusters' development history shows that they give a significant boost to regional development, improvement of economic activity areas, including the level of small and medium-sized businesses.

To highlight the region's most promising areas for the formation and development of clusters it is necessary to analyze the sectoral structure of the area's economy and to identify economic sectors showing the highest efficiency on the following criteria:

- $\quad$ The growth rates of the production, sales, and services above average in the regional;

- High levels of investment at the sectoral level;

- Profitability of activity above the industry`s average indicators.

In order to identify suitable to the specific conditions of forms of organization of clusters it is necessary to conduct serious analytical work on the relationships between objects of cluster policy. Here are three main options for the business combination into clusters (depending on the method of functioning of the cluster system):

- Economic activity in related sectors in the region, usually tied to academic institutions;

- Company elements of vertical production chains that make up the adjacent stages of the production process;

- Highly aggregated industry. 
In identifying promising areas of clustering in a particular area can be used a variety of approaches. For example, the experts of the Organization for Economic Cooperation and Development (OECD) suggest the use of analysis of inputoutput balance, allows to detect the communications value chain. As a result, the company determined that make up the cluster.

Studies conducted in European countries indicate that individual states tend to develop their own methods of identifying clusters Pylypenko I.V. (2005) \& Novikov V.S., Klochko E.N., Yarushkina E.A., Zhukov B.M. \& Dianova V.A. (2015) (Table 1).

Table 1 - Methods to identify clusters in Europe

\begin{tabular}{|l|l|}
\hline State & $\begin{array}{l}\text { Methods of identifying the cluster } \\
\text { When identifying clusters into account the following principles: } \\
\text { - The existence of a clear horizontal and vertical linkages between firms; } \\
\text { - Focus on the consumer cluster. } \\
\text { The process of identifying a cluster included the following steps: } \\
\text { - Considered a large company, then use the value chain all stood firm, supplying semi-finished products, services and support services. } \\
\text { We continue to identify horizontal and vertical communication; } \\
\text { - Selected organizations providing service cluster; } \\
\text { - Considered governmental organizations, influencing the development of the cluster. }\end{array}$ \\
Belgium & $\begin{array}{l}\text { When you select the cluster to use a Leontiev's "input-output" matrix } \\
\text { The method used Leontiev transformed into M-method or method of Maxim, which was applied in two directions interchangeable. At first } \\
\text { we considered all direct communication (delivery of products that are important for suppliers), and then examined all the supplies that are } \\
\text { important for buyers. The cluster ranked as those cells of the matrix, where the answers to suppliers and customers intersect. } \\
\text { We consider the following criteria to be met by clusters detected: }\end{array}$ \\
Norway & $\begin{array}{l}\text { - Settled the labor market; } \\
- \text { The employment rate of at least } 3 \text { (the ratio of the share of employment in certain sectors in the cluster to the share of people employed } \\
\text { in this industry in Norway as a whole); } \\
\text { - No less than } 10 \text { companies specializing in one industry and providing at least } 200 \text { jobs. } \\
\text { Research to identify clusters is conducted in four phases. The first stage involves the comparison of export quotas of Finnish goods with } \\
\text { Finland }\end{array}$ \\
$\begin{array}{l}\text { a quota of Finnish exports in world exports (excluded sectors with a negative trade balance, as well as industry, supplying products } \\
\text { geographical neighbors). The second step was a list of companies from sectors remaining in the study. These organizations and their } \\
\text { manufactured goods were grouped into functional relationships, allowing for the geographical boundaries of the clusters. In the third } \\
\text { stage, experts estimated closeness horizontal vertical links between firms. The last step involves the direct study of clusters in Finland in } \\
\text { order to improve their competitiveness. }\end{array}$ \\
\hline
\end{tabular}

Economists E. Bergman and E. Feser identify the following approaches to identify potential clusters in a particular area:

- expert opinions;

- calculation of specific indicators (for example, the localization ratio);

- $\quad$ formation of input-output tables (ISB) to study commerce or innovation;

- $\quad$ usage of graph theory;

- conducting polls (surveys).

Thus there is a need to clearly define the characteristics of the clusters based on regional and industry specifics. It should be noted that an adequate reflection of the economic and mathematical phenomena and processes in the field of regional development is possible only with the continuous improvement of an appropriate system of statistical observation. In this regard, it is advisable to ensure the development of statistical information gathering in the field of cluster development in the following areas:

- Updating of the program of statistical monitoring of institutional reforms in line with international standards;

- Comparison of the data within the regions with the general results of the country and the results of European statistical surveys;

- Development of methodological approaches to the statistical analysis of regional clusters, including an analysis of their development, identifying areas that have scientific, technical and innovative potential of access to world markets of high technology products;

- Development of methodology and organization of statistical monitoring of the production and marketing of high-tech products, including exports.

In domestic practice to identify potentially promising clusters are used:

- methodology developed in the South Russian center technologization of the regional and municipal activities at the Institute of Economy and Foreign Economic Relations of the Rostov State University (Ermishina A.V., 2015 \& Karepova, et al., 2015);

- analytical model of consulting firm «Boston Consulting Group» (BCG), adapted to the regional industrial 
system.

- It should be noted that the application of one or another technique must take into account certain disadvantages of each (Table 2).

Dwell primarily on the analysis of these approaches.

The technique, developed in the South Russian center technologization regional and municipal activities, involves three steps:

1. Quantitative analysis of competitive sustainability.

2. Qualitative analysis of the competitive conditions of stability.

3. Clusters` analysis.

The first phase involves the calculation of these statistics, the coefficient of localization $(\mathrm{Cl})$, the ratio of per capita production (Kd) and the coefficient of specialization $(\mathrm{Kc})$.

Table 2 - Advantages and disadvantages of methods to identify clusters

\begin{tabular}{|c|c|c|}
\hline Technique & Technique`s advantages & Technique`s disadvantages \\
\hline Expert opinions & $\begin{array}{l}\text { Suffice cost- and time-effective, detailed } \\
\text { information obtained }\end{array}$ & $\begin{array}{l}\text { Unstructured information, it is very difficult to } \\
\text { classify clusters }\end{array}$ \\
\hline $\begin{array}{l}\text { Special indicators (coefficient of } \\
\text { localization, etc.). }\end{array}$ & Not costly, can complement other techniques & $\begin{array}{l}\text { Focusing on the sectors and spheres rather than } \\
\text { the clusters. }\end{array}$ \\
\hline Tables MOB: trade & $\begin{array}{l}\text { Often, the main source of information on the } \\
\text { interaction of industries, detailed and accurate } \\
\text { information }\end{array}$ & $\begin{array}{l}\text { Do not take into account the supporting } \\
\text { institutions, identification of spheres can be wrong }\end{array}$ \\
\hline Tables MOB: Innovation & $\begin{array}{l}\text { The main approach is to measure the } \\
\text { relationship between sub-sectors }\end{array}$ & The absence of such statistics in many countries \\
\hline Graph Theory & $\begin{array}{l}\text { Visualization helps the analysis and } \\
\text { interpretation of the results }\end{array}$ & The software is still limited \\
\hline Reviews & $\begin{array}{l}\text { The flexibility in collecting information on the } \\
\text { cluster information is always up to date }\end{array}$ & It is expensive, difficult to interpret the results \\
\hline
\end{tabular}

According to this technique, the spheres of market specialization, in which there are clusters or their creation is possible, are the spheres with values calculated indices from 1 and above (considered at the next stage in the first place). At the same time, the exclusion of potential sites clustering of any branches, not falling under this condition occurs.

In the second stage takes place the qualitative analysis of the competitive conditions of stability. Developers offer techniques to analyze the presence of these conditions with the help of quantitative and qualitative indicators, integrating into a summary score for each condition (Table 3).

Table 3 - Analysis of the availability of competitive conditions of stability

\begin{tabular}{|l|l|l|}
\hline Competitive conditions of stability & Quantitative evaluation $\quad$ Qualitative evaluation \\
Factors of production & Overall score - available / unavailable \\
Demand in the domestic market & Overall score - interested / uninterested \\
Competitive industry suppliers and other related industries & Overall score - Presence / absence \\
Factors motivating the formation of effective strategies & Overall score - Presence / absence \\
\hline
\end{tabular}

The analysis of the primary species formed sixteen sectors, which by means of the enlarged groups merged into three blocks:

1) industries with high potential for the existence of the cluster (required minimum information support and control action);

2) industries in which you can create clusters (requires targeted long-term control actions);

3) industries in which clustering requires a significant cost, not commensurate with the expected effect.

The first two groups of industries go to the next stage of transition.

The third stage involves the analysis of potential clusters, which can be carried out in different directions:

- institutional organization of clusters;

- internal motivation to initiate and maintain clusters;

- comparative competitiveness of cluster members;

- evaluation of strategic potential clusters. 
Thus, the above-considered approach allows the evaluating the potential and success of clustering in the region.

Another method, used in domestic practice is BCG matrix (Akhmetzyanova E.R., 2003), adapted to regional industrial systems. When modifying the matrix BCG, used to identify clusters of parameters 'relative share of the industry "and" growth industry "may be replaced by the parameters' share of industry in total sales of industrial products in the region $(R)$ " and "the share of industry in the pace of changes in the volume of industrial sales production region (T). "

For each sector, the parameter $\mathrm{K}$ is calculated by the following formula:

$$
K_{i}=\frac{Y_{i}}{Y_{o}} \cdot 100 \%
$$
period;

Where $\mathrm{Ki}$ is the share of the i-th branch in total sales of industrial products in the region during the reference

Yi - sales of the i-th branch in monetary terms in the base period;

Yo - the total sales volume of industrial production in the region in terms of money in the base period;

$\mathrm{i}$ - number of the industry, which is part of the industrial production;

$\mathrm{n}$ - the number of industries included in the industrial production.

Wherein:

$$
Y_{o}=\sum_{i=1}^{n} Y_{i}
$$

The second indicator is the ratio of $\mathrm{T}$ - "share of industry in the pace of change in the volume of sales of industrial products in the region" during the base period of a linear trend.

Figure 3 shows an example of a modified BCG matrix.

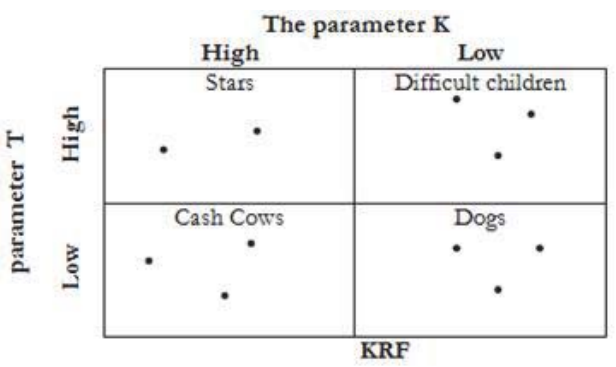

Figure 3 - Modified BCG matrix, used to identify the cluster structures

It should be noted that the product replacement options provided an opportunity to use the information when the actual construction of the matrix, thus, improve the accuracy of detection of cluster structures.

According to its potential and structure of cluster policy is precisely the set of activities that can contribute to solving the problem of improving the competitiveness of both regional and national economy through the development of competitive markets, increased innovation of various sectors of the economy, accelerated development of small and medium-sized businesses, promotion of local initiatives and intensification of cooperation between government, business and academia.

The relationship of participants in the cluster must be a strategic alliance with the appropriate elaboration of common objectives and strategies, to act as a single entity of competition, more efficient use of resources and information based on the operation of the network center, forming a common strategy for coordinating the activities of partners, to develop their core competencies, shuttle service technologies. Such a center should accumulate and analyze customer requirements, information about new technologies available on the market resources, the actions of competitors, etc. In the next stage, he is looking for activities, the formation of production chains; allow reacting flexibly to market demands. In this regard, one of the most important characteristics for the selection of the participants of this chain is the duration of the technological cycle of production capacity, the ability to create added value. Control functions of the production and money flows in the network and it are advisable to allocate a separate firm, specialized in this area. During the implementation of the strategy of the cluster participants need to work together to develop (Akhmetzyanova E.R., 2003; Zelinskaya, et al. \& Borodin E.A., 2015):

- Commodity policy, i.e. plan and develop the assortment structure, to evaluate the competitiveness of goods (services); 
- Pricing policies;

- Communication policy, for example, planning of exhibitions and fairs, to create a local brand of the cluster;

- The policy of formation of the sales network (selecting distribution channels and product distribution, sales forecast).

Now allocate the cluster policy of the two generations:

1) A set of measures of federal and regional authorities to establish public bodies support clusters, determination of their field of activity, set of activities for the identification of clusters;

2) An individual approach to the development of each particular cluster on the basis of full information on existing clusters and preconditions of their formation.

M. Enright (Enright, M.J., 2002) put forward four types of cluster policy: the catalyst one, the supporting one, directive one, and interventionist one. If the first type provides only for bringing together stakeholders with limited private support, the second - complements its investments in infrastructure, education and marketing, and the third provides for special programs to change the specialization of regions, then it shifts to the fourth state control action cluster members, the formation of its specialization, responsibility the further development of the cluster.

Currently, experts described the seven main approaches to the formation of clusters, based on the combination of which the choice of a cluster strategy is made (Efimychev Y.I., 2005):

- Geographical: the construction of spatial clusters of economic activity, from local to global;

- Horizontal: a few industries or sectors may be included in larger clusters;

- Vertical: in clusters may attend a series of adjacent steps of the manufacturing process;

- Lateral: cluster together different sectors, providing economies of scale, leading to promising new combinations (for example, a multimedia cluster);

- Technology: the totality of sectors using a technology (such as biotechnology cluster);

- Focal: a cluster of firms, rounding up a single center - the company, research institute or university.

Clustering affect the three main components of the region's economic growth - technological, socio-economic and resource that the cluster approach makes it one of the most promising tools for development areas. At the same time, in the context of globalization increase the competitiveness is not necessarily linked exclusively to the geographical characteristics of the clusters.

Forms of realization of cluster policy are differentiated depending on the forms of organization of production and the location of the cluster. Fostering cluster development should be based on the creation of the federal government space-less clusters at the national level, supporting the competition, the introduction of educational and environmental regulations and standards at the expense of the legislative and contractual activities.

At the interregional level should be developed appropriate strategies for regional development, clustering, and specific projects based on public-private partnership. Spatial clusters at regional level and supported the establishment of the municipality of the brand in the region, the promotion of products in the Russian and foreign markets. A special role belongs to the cluster initiative at the level of municipalities, local governments, from which, in the first place, it is required to support the development of networks of companies in related sub-sectors, to ensure contacts between the authorities, business organizations, research and educational institutions.

The mechanisms of the state of cluster policy should ensure the full utilization of the competitive advantages of specific regions, to encourage the creation of new competencies and, ultimately, to ensure access to the leading position in the international competition of the Russian Federation, its regions, companies and organizations.

The regional authorities can contribute to the organizational development of clusters in the following areas:

1. Formation of a specialized organization of the cluster, ensuring coordination of its members, which can be created in a variety of legal forms. It should be understood that the functions specified organization may be assigned both for newly constructed and already existing organizations.

2. Development of a cluster development strategy and action plan for its implementation, including the development of a set of clustered projects and measures aimed at creating favorable conditions for the development of the cluster, based on the analysis of barriers and opportunities for cluster development.

3. Establish effective communication between members of the cluster.

4. Implementation of measures to promote cooperation between members of the cluster (the organization of conferences, seminars, working groups, the creation of specialized Internet resources and electronic mailing lists).

Using cluster policy as an instrument of innovation development, it is necessary to define the target parameters of major regional industrial clusters. On this basis, the federal government will be able to determine the place and role of the economy in each region in socio-economic and spatial development of the country. Business and the region will see 
specific goals and priorities for economic development, to feel concrete support and commitment of the federal center. It is necessary to create a legal and financial base of support and development of regional industrial clusters.

It should be noted that the cluster will not be issued as a single legal entity and does not constitute a single economic entity. Strategic planning of the development of the cluster in the case of active participation in the development of a cluster of power is carried out according to a specific scenario. It is often joint planning of business groups, business entities, temporarily uniting for joint projects.

Clusters of being cross-sectoral entities, increasing interconnectivity of the industries of the territorial economy through more rapid dissemination of specific to the region (to ensure the appropriate conditions) technology, skills, information and marketing (specific competitive advantages in this as it flows through the enterprise and industry). This means acceleration of innovation, which is the basis not only to increase productivity, but also to update the strategic differences (advantages), maintaining a dynamic of competition (Efimychev Y.I., 2005).

An important reason for the need for self-development cluster in the region is a series of management of regional development Prokhorov V. (2010). The real benefits of cluster development, as experience shows, there are 5 - 7 years, while the management of the region is limited to electoral cycle in $4-5$ years, making it difficult to conduct a coherent long-term strategy for the region.

The mechanisms of the state of cluster policy should ensure the full utilization of the competitive advantages of specific regions, to encourage the creation of new competencies and, ultimately, strengthen the position of Russia as one of the world leaders.

Note that not all closed on specific areas: the development of the global economy and the emergence of computer communications, covering the whole world, created a new, virtual organizational structure of enterprises. It is based on the following principles:

- The rejection of the territorial integrity of the enterprise. There is no need to make any part or parts, if someone can make them better, faster and cheaper;

- Partners in the joint production of the product are there as long as their shipments meet the standards of quality and technological level. If either the equipment, technology or partners is outdated and, you need to look for new ones;

- In the global economy the search for partners must be carried out around the world. As history shows, inventions and discoveries are made in different countries and often in small firms or individuals;

- Having the flexible structure is beneficial to the company; it allows using existing and acquired resources with maximum efficiency;

- Due to the rapid development of technology it is not profitable to invest big money in the purchase of expensive equipment, stationary facilities, especially if it is not known how much of the product will be released;

- Reducing the unproductive expenditures, primarily the management, is advised.

Accordingly, virtualization involves a change in approaches to the formation of clusters in the economy: the importance of changing the ratio of common descriptive characteristics of the cluster - the territorial localization, accessories companies to related sectors or subsectors, and the close links between them. The proximity has less and less importance to maintain contacts between organizations - members of the cluster Shutilov F.V. \& Prokhorov V.V. (2012). Because of the interaction of a single contract is not participants in the cluster, the boundaries are blurred economic cluster. Therefore, to more accurately define it as a group of companies united by a single material, financial and information flows. A cluster is a legal entity, its structure is not defined the same for all the agreement. However, the contractual relationships between the individual enterprises have a sustainable long-term nature. While enterprises cluster serve a particular sector of the market, that is, aimed at buyers of certain products in a particular territory, the enterprises themselves are not necessarily geographically located in this area.

As a result, the organization of work within the cluster requires the creation of a new type of control center, whose goal is to solve all the complex problems that are not directly connected with the manufacture of products. To this end he carries out all external processes to support the production, and organizes virtual enterprises and their interaction. Center determines which products will be produced, finds customers and buyers, preparing the necessary documentation, on the basis of which the production will be done directly. After that he will organize a virtual company and then performs only control over its activities on the financial performance.

We note that clusters will be formed depending on the tasks that need to be addressed in the course of their operation. Thus, one and the same organization may enter into various clusters depending on the region, which is selected for the implementation of specific activities of any individual project. Economic clusters are thus uniform in coverage units processing chain: in some cases they will only unite suppliers and wholesale companies, while others are 
characterized by their wider communication, starting with the supply of raw materials and finishing products to manufacturers retail sales.

The need to consider the features discussed requires a review of approaches to the formation of clusters and serves as further proof that it is inappropriate clustering 'outside'. Regional authorities need only ensure that the necessary conditions for creating a "breeding ground" for the growth of virtual enterprises, to solve problems hindering their development.

These problems include:

- The need to create technological systems for the organization of e-society in which potential partners could offer their products and services;

- The formation of the economic conditions under which any producer, from a large corporation and ending with the inventor, create a new technology, it would be advantageous as quickly as possible to put your product in the electronic marketplace;

- The creation of a verification mechanism responsible and reliable partner, a sort of "credit history of trust";

- The development of a legal framework to enter into contracts, matching the legislation of different countries and regions with their subtleties and differences;

- Simplification of the issues of information exchange, coordination of data exchange standards, harmonization of the various information products and systems.

The benefits to business organizations, members of the cluster include the following points:

1. Reducing the barriers to entry into the industry.

2. Reduce costs through economies of scale.

3. The ability to extend the competitiveness of the leading companies in the cluster, its immediate surroundings, gradually creating a sustainable network of the best suppliers and consumers.

4. Enhancing innovation, the development of advanced technologies due to their close ties with the developers.

5. Minimizing the time span from idea to practical implementation.

6. Optimization of production and processes.

7. Access to results of small businesses capital specialized studies carried out at the expense of all the cluster members, and hence the ability to withstand the increased competition in globalized markets.

8. Saving economic independence and the possibility to carry out intra-competition.

9. The ability to minimize the risks of the operation at the expense of lowering the profitability level of the enterprise companies of the cluster.

10. An intensive exchange of information, financial, human, innovative resources.

Since the cluster policy is quite effective alternative to traditional industrial policy is relevant task of assessing the effectiveness of the cluster. At the same time, quantitative methods for assessing the effectiveness of the integrated cluster structures are very diverse. The most commonly used traditional indicators of financial performance of individual members of the integrated group - the ratio of costs and benefits; straight overall performance of the individual blocks of the integrated cluster structure (financial, industrial, research, commercial) and direct performance indicators of association as a whole (the valuation of the company, the market value of assets, the value of total turnover for a certain period, gross profit, etc.).

There are different approaches to the evaluation of a synergistic effect, which refers to "effect caused by coordinated in space and time the action is by nature diverse mechanisms that lead to qualitative changes in the system" Avdonina S.G. (2012).

The concept of synergy (synergy) was first introduced by Nobel laureate Hermann Hakenenom. Now under synergy we understand the science of self-organization in various systems, regardless of the type of which each of them is inherent in the concept of emergence - inconsistency overall effect of different mechanisms of action in the arithmetic sum of the effects from the action of the parts making up the whole. Consideration of a group of organizations that make up the cluster structure as a synergetic system suggests that the integration process should lead to the emergence of a synergistic effect in which the income from the joint operation of enterprises exceed the amount of income generated by the same companies that operate independently.

This reveals the following synergies:

- Administrative synergies;

- Synergy infrastructure;

- Financial synergies;

- Operational synergies;

- Synergies in sales. 
If we talk about methodological aspects of the quantitative estimation of synergies within the cluster formation, it is possible in principle to allocate the following directions of the organization of this evaluation.

Firstly, the assessment can be done by comparing the resultant performance indicators and cluster group of companies in a "non-clustered".

It can be both absolute and relative terms. In particular, this could be a reduction of unit costs or increase earnings at a given level of investment.

Secondly, often the cluster organization pursues political objectives associated with maintaining enterprise attributable to certain economic activities or certain territory. In such cases, the enterprise cluster can receive subsidies from the budgets of different levels or investment injections on favorable terms, tax breaks. In this case, the formal basis of these external influences can also be attributed to the additional effect of the existence of the cluster.

Of course, the more interest is the first type of assessment. However, the methodological difficulty of implementation lies in the choice of an adequate method of predicting the state enterprise "without a cluster."

Actual quantification of synergies cluster can be based on the methods of valuation of companies in the cluster. As a rule, the valuation of companies is based on three main approaches: cost, market comparisons (analog), income. The most accurate quantification of the synergetic effect of the cluster can be accessed by using the income approach to valuation of companies, as well as the total profit of enterprises cluster is the result of diffusion of innovations within the cluster of related and affiliated companies, to stimulate competition between the companies of the cluster and a number of other conditions.

With this method, a synergistic effect of the cluster can be estimated as the total net profit and depreciation charges resulting from the implementation of investment projects form a cluster.

A noteworthy one is the system of assessing the effectiveness of proposed NI Klepikova Klepikova N.I. (2013), which takes into account that according to the statement of methodical recommendations on the implementation of the cluster policy, clusters are five fundamental characteristics (Guidelines for the implementation of the cluster policy in the Northern regions of the Russian Federation, 2008):

1. Availability of competitive enterprises.

2. The presence of the region / area of competitive advantage for the development of the cluster.

3. Geographical concentration and proximity.

4. A wide range of participants and the presence of a "critical mass."

5. The presence of communication and interaction between the cluster members.

For each of these characteristics cluster developed its own evaluation criteria.

\section{Concluding Remarks}

In general, the sequence of steps of evaluating the effectiveness of establishing a regional cluster should appear as follows Hasheva Z.M. \& Ismailov R.A. (2004):

1. Determination of the importance of the project for the region

2. Determining the cost-effectiveness of the project

3. Risk assessment of the investment project

4. Assessment of synergies

5. Analysis of the results and the choice of alternative solutions

Summing up the above analysis, we note that through the use of sound methods of evaluating the effectiveness of using the cluster approach to the socio-economic development of regions of the Russian Federation can be expected to achieve the following positive effects:

- Attracting more investments and increase investment rating of individual businesses, and cluster formations and regions as a whole;

- Employment growth in small business forms involved in the cluster;

- Improving living standards in the region;

- The sustainable economic development of the region and achieve a higher level of economic efficiency of enterprises belonging to the clusters.

\section{References}

Porter, Michael E. (2005) Competing: Trans. from English. M.: Publishing House "Williams". pp. 608.

Shutilov, F.V. (2011) The necessary and sufficient conditions for a cluster structuring economic systems // Kazan Science. № 8. pp. 120- 
123.

Zakharova, EN \& Kovalev I.P. (2013) Formation of a medical cluster as the direction of integration interaction of the regional medical sector // Herald of Adygeya State University. Episode 5: The Economy. N4 (131). pp. 216-222.

Pylypenko, I.V. (2005) The competitiveness of countries and regions in the world economy: the theory, the experience of small countries in Western and Northern Europe. Smolensk: Ojkumena. pp. 495.

Ermishina, A.V. (2015) The competitiveness of the region // (electronic resource). Access: http://www.cFin.ru/management/strategy/ competitiveness.shtml.

Akhmetzyanova, E.R. (2003) Creation and development of industrial clusters: the dissertation of the candidate of economic sciences. Kazan. pp. 169.

Borodin, E.A. (2015) Klasterny mechanism of increasing the competitiveness of economic systems // Almanac RIEPP "Science, innovation, education". pp. 139-157.

Enright, M.J. (2002) Regional Clusters: What we know and what we should know. Paper prepared for the Kiel Institute International Workshop on Innovation Clusters and Interregional Competition. pp. 18.

Efimychev, Y.I. (2005) Industrial clusters and economic growth. / Y.I. Efimychev and I.V. Zakharov // Bulletin of the Nizhny Novgorod University. N.I. Lobachevsky. Series: Economics and Finance. № 1. pp. 15-18.

Prokhorov, V. (2010) The potential of industrial clusters in the development of the territory // Business Law. Economics and Law Journal. № 3. pp. 326-328.

Shutilov, F.V. \& Prokhorov V.V. (2012) Territorial development of economic systems based on the cluster approach. Krasnodar Univ YUIM. pp. 127.

Avdonina, S.G. (2012) The synergistic effect of cluster formation and the parameters of its evaluation // Regional economy and management: electronic scientific journal. № 1 (29).

Klepikova, N.I. (2013) Evaluating the effectiveness of the creation of an industry cluster // Basic Research. № 4 (Part 4). pp. 934-939.

Guidelines for the implementation of the cluster policy in the Northern regions of the Russian Federation. (2008) [electronic resource]. URL: http://www.council.gov.ru/journalsf/cat3/journal14/2008/number238.html

Hasheva, Z.M. \& Ismailov R.A. (2004) Managing the development of a municipal industrial complex: monograph / Krasnodar Univ South. Management Inst. pp. 155.

Novikov, V.S., Klochko, E.N., Yarushkina, E.A., Zhukov, B.M. \& Dianova, V.A. (2015) On peculiarities of the virtual economy of modern Russia: categories, virtual relationships, educational constructs. Mediterranean Journal of Social Sciences, 363 (247-257).

Karepova, S.G., Karabulatova, I.S., Klemovitsky, S.V., Novikov, V.S., Stratan, D.I. \& Perova, A.E. (2015) New approaches to the development of methodology of strategic community planning. Mediterranean Journal of Social Sciences, 363 (357-363).

Zelinskaya, M.V., Mezhlumova, V.R., Boltava, A.L., Tarasova, O.Y. \& Gadzheiva, E.Y. (2015) Higher education of Krasnodar Krai: economic aspects. Mediterranean Journal of Social Sciences, 363 (225-235). 